\title{
Final Report \\ Development of Multielement SQUID Arrays for Magnetic Source Imaging
}

W. V. Hassenzahl

T. A. Casper

RECEIVED

D. E. Miller

OCT 061995

OSTI

June 1995

This is an informal report intended primarily for internal or limited external distribution. The opinions and conclusions stated are those of the author and may or may not be those of the Laboratory.

Work performed under the auspices of the U.S. Department of Energy by the Lawrence Livermore National Laboratory under Contract W-7405-ENG-48.

$$
\text { DISTRIBUTION OF THIS DOCUMENT IS UNLIMITED }
$$




\section{DISCLAIMER}

This document was prepared as an account of work sponsored by an agency of the United States Government. Neither the United States Government nor the University of California nor any of their employees, makes any warranty, express or implied, or assumes any legal liability or responsibility for the accuracy, completeness, or usefulness of any information, apparatus, product, or process disciosed, or represents that its use would not infringe privately owned rights. Reference herein to any specific commercial product, process, or service by trade name, trademark, manufacturer, or otherwise, does not necessarily constitute or imply its endorsement, recommendation, or favoring by the United States Government or the University of California. The views and opinions of authors expressed herein do not necessarily state or reflect those of the United States Government or the University of California, and shall not be used for advertising or product endorsement purposes.

This report has been reproduced directly from the best available copy.

Available to DOE and DOE contractors from the Office of Scientific and Technical Information P.O. Box 62, Oak Ridge, TN 37831

Prices available from (615) 576-8401, FTS 626-8401

Available to the public from the National Technical Information Service

U.S. Department of Commerce 5285 Port Royal Rd. Springfield, VA 22161 


\section{DISCLAIMER}

Portions of this document may be illegible in electronic image products. Images are produced from the best available original document. 


\title{
Final Report
}

\section{Development of Multielement SQUID Arrays for Magnetic Source Imaging}

\author{
93-SR-132 \\ FY 1993: $\$ 142,000$ \\ PI: W. V. Hassenzahl \\ T. A. Casper, and D. E. Miller
}

Superconducting quantum interference devices (SQUIDs) were initially developed in the late 1960 s as biomagnetic detectors to monitor electrical activity in the body. Research in this area has increased in recent years as electronics and computer diagnostics have improved. The basis of this proposal was to asses: 1) the advantages of using this technique over other technologies and 2) the requirements for development of a complete system that would advance the state of the art. In our assessment of this technology, we collaborated with the Medical School at the University of California, San Francisco (UCSF), General Electric (GE), Biomagnetic Technologies (BTi), and Conductus, each of which has unique expertise in biomedical applications. UCSF is one of the foremost clinical institutions in the US developing imaging techniques. GE is the primary US supplier of medical imaging systems. Conductus is the major US supplier of SQUIDs and BTi is a developer of SQUID array systems.

A major conclusion of this effort was that the application of SQUID arrays to imaging of cardiac activity is medically relevant because about $4 \%$ of the population could benefit from clinical evaluations based on a biomagnetic heartimaging system (BHIS). In addition, magnetic signal strengths from currents in the heart are typically 1000 times larger than those from the brain, making the cardiac application less susceptible to environmental magnetic disturbances. Thus, our primary focus is to develop clinical applications for heart imaging, while imaging of the brain and other biological functions are of secondary 
interest. The overall cost to the medical health care community is a crucial issue that may determine if this technology will be successfully applied.

We focused our effort in three main areas. The first was a determination of requirements to develop the BHIS for clinical applications. The second is an assessment to determine the impact of LLNL-based materials fabrication techniques on SQUID detectors. The third is an assessment of the computational requirements for clinical applications.

We identified major elements and outlined a program that should lead to the successful development of a clinical BHIS system. The major elements of such an effort would include the following:

- SQUID system configuration

- SQUID power supply development

- Front-end sensor electronics

- Cryogenics and packaging

- Shielding issues and signal multiplexing

- Workstations, software and database design

- Systems Engineering

- Patient handling and gantry

- Algorithms for inverse problem solutions

- User/physician interface

- Prototype development

In establishing these concepts, it was necessary to develop a memorandum of understanding to promote the free exchange of ideas. Because of a reduction in interest on the part of GE during the course of this work, this effort shifted to an interaction with the BTi company that has prior experience in making SQUID imaging systems. BTi will provide the use of a magnetically and electrically shielded room and one of their instruments for use by UCSF and LLNL for concept testing in the early part of 1994.

We investigated the benefits that LLNL-based materials-fabrication techniques would have on the development of more suitable SQUID-detector systems. Use of the LLNL Electronics Engineering Research Division capabilities for producing extremely precise arrays of conductors is applicable to 
development of magnetic-field measurement coils for use as the input to SQUID imaging systems. Very precise magnetic-field gradiometer components would provide a method for reducing the noise caused by ambient magnetic fields, thereby enhancing signal detection capability. If the process is as effective as calculations suggest it will be, use of precisely fabricated sensor arrays would eliminate the need for an expensive (approximately $\$ 500,000$ ) magnetically shielded room, thereby lowering the overall cost of a BHIS system. This tremendous cost reduction would improve the commercial attractiveness of the resulting system, allowing installation of more units at several locations as well as an overall reduction in the cost per evaluation.

Finally, we completed an assessment of the computer-processing applications required for a clinical biomagnetic imaging system. Although several groups at LLNL are developing computer-aided tomographic analysis techniques, a BHIS will require development of near real-time inverse problem solutions for analysis and display of the data by a physician. Networkdistributed computing technology relevant to requirements for a BHIS is being applied to computationally similar problems at LLNL. These distributed computation concepts could be applied directly on existing computer systems present in clinical institutions such as those involved with advanced radiological evaluations.

In summary, we have characterized the medical need, fabrication issues, and computational problems associated with development of a BHIS for clinical applications. Future efforts in this area could include data handling and analysis using an imaging array that BTi is installing at UCSF. We could also develop new signal processing algorithms and displays using data from existing human brain measurements available to LLNL. Our long range goal of developing a clinical BHIS system still remains. 